\title{
Obituary
}

\section{Bertram Mandelbrote}

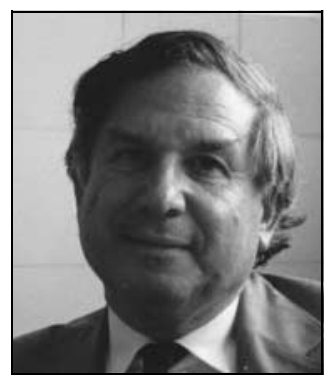

Formerly Physician Superintendent, Littlemore Hospital, Oxford, and Honorary Clinical Lecturer, University of Oxford

Bertram Mandelbrote was one of the pioneers who brought an end to the institutional care of people with a mental illness and showed how therapeutic community methods could contribute to their rehabilitation.

He was born on 22 October 1923 in Cape Town, where his father was professor of history in the university, and grew up there. In 1946, soon after qualifying in medicine, Bertram won a Rhodes Scholarship to Oxford where he carried out one of the earliest studies of copper metabolism in neurological disease. From Oxford he moved to the Hammersmith Hospital in London for further medical training and quickly obtained an MRCP (and a Fellowship in 1964). Throughout this time Bertram was becoming increasingly interested in the psychological problems of his patients and decided to train in psychiatry at the Maudsley Hospital. Having completed psychiatric training, he won a Dominions Research Fellowship to study the psychological aspects of thyroid disease with Eric Wittkower at McGill University in Montreal. Although he greatly enjoyed this second period of research, soon after his return to the Maudsley he decided that he would gain experience of the newly introduced 'open door' methods of treatment for patients detained in large mental hospitals.

Thus it was that in 1954 Bertram Mandelbrote moved to Warlingham Park Hospital to work with T. P. Rees, one of the pioneers of the new approach. Rees had unlocked closed wards, made relations between staff and patients less formal, and introduced rehabilitation to prepare patients for life outside hospital. Mandelbrote thrived in this new environment and after a year, with strong encouragement from Rees, accepted the post of Physician Superintendent of Horton Road and Coney Hill hospitals in Gloucester. There Mandelbrote set about changing the severely institutional regime of these two hospitals, adapting the methods that he had seen in use at Warlingham Park. Within a short time he had won over sceptical staff, opened wards, recruited help from members of the local community and had begun to change the lives of his patients. In the ensuing years, he received many invitations to describe these achievements both from across the UK and the USA. In 1959, Mandelbrote was offered the post of Physician Superintendent of Littlemore Hospital in Oxford and, with the changes in Gloucester firmly in place, he felt ready to take up this new challenge.

At Littlemore, Mandelbrote began to institute the reforms that had worked well in Gloucester. Although all his colleagues were convinced by the need to move from an institutional model of care, not all favoured the therapeutic community approach within the hospital. It was agreed to divide the wards, with half run as a therapeutic community and the rest conducted in a more conventional, but still forward-looking, manner. Realising the importance of facilities outside the hospital, Mandelbrote set in train other initiatives and these won general support. He initiated what was to become the largest and most comprehensive network of group homes in the country, recruited an effective League of Friends, and gained the support of local businessmen to develop sheltered work. All these are now recognised as essential elements of good psychiatric care but at the time they were innovative departures from established practice. To achieve so much required an exceptional capacity to engage and motivate others, to choose colleagues wisely, to delegate effectively, to trust and support staff and, at times, to contain their anxieties. Within a short time the success of these activities was evident in a reduction of the number of in-patients and a range of provisions for those who were living outside the hospital.

Despite this intensive involvement in the planning and delivery of services, Bertram did not lose his interest in research. He obtained funds to evaluate his therapeutic community approach, and rekindled his former interest in endocrinology in a collaboration with the renowned Oxford neuroscientist, Professor Geoffrey Harris. In recognition of these activities and of his contribution to teaching, Mandelbrote was appointed honorary clinical lecturer in the Oxford University's medical school. When, in 1969, a University department of psychiatry was established, he was one of its strongest supporters, and collaborated with members of the department to develop his original endocrine studies into a broader programme of neuroendocrinology.

Bertram thought strategically. He foresaw, earlier than most, the increasing specialisation of psychiatry and was instrumental in the creation in Oxford of dedicated services for the elderly, for people who could be helped by intensive psychotherapy, and for those with drug and alcohol problems. For the last, he worked with Peter Agulnik in Oxford to set up an innovative therapeutic community, which is still active and recently won a Centre for Social Justice Award. For people with less severe emotional problems he created a pioneering walk-in counselling centre. $\mathrm{He}$ worked to extend the traditional roles of psychiatric nurses and occupational therapists and to improve their training. He was at various times a trustee of the Dorset House School of Occupational Therapy and chairman of the Elizabeth Casson Trust.

In 1987, Bertram suffered an extremely serious car accident and spent many weeks in intensive care. He fought his way back to health with characteristic courage and determination and resumed his full duties until he retired in 1988. Thereafter, he continued his work with people who had drug dependence and in forensic psychiatry until shortly before his death. The hospital which he had worked so hard to transform was eventually closed but his contributions were given lasting recognition within the ensuing residential development by the naming of a street after him. He will be recalled for his concern for the most severely ill and disadvantaged of people with mental illness, and for the clear thinking, energy and determination which he brought to bear on their behalf. He will be remembered also as one of the pioneers of therapeutic community methods, and of care in the community.

Bertram Mandelbrote died on 25 November 2010, aged 87. He is survived by his devoted wife Kathleen, to whom he had been married for 61 years, and by his two sons.

Michael Gelder

doi: 10.1192/pb.bp.111.034389 